\title{
Prediction of fatigue limit of journal bearings considering a multi-axial stress state
}

\author{
Christopher Sous \\ Institute for Machine Elements and Machine Design, RWTH Aachen University, Aachen, Germany \\ Henrik Wünsch \\ Institute of Material Applications in Mechanical Engineering, RWTH Aachen University, Aachen, Germany \\ Georg Facobs \\ Institute for Machine Elements and Machine Design, RWTH Aachen University, Aachen, Germany, and \\ Christoph Broeckmann \\ Institute of Material Applications in Mechanical Engineering, RWTH Aachen University, Aachen, Germany
}

\begin{abstract}
Purpose - The purpose of this paper is to investigate the applicability of the quadratic failure hypothesis (QFH) on journal bearings coated with a white metal sliding layer on the prediction of safe and unsafe operating conditions. The hypothesis covers operation conditions under static and dynamical loading.

Design/methodology/approach - Material tests and elastohydrodynamic, as well as structural, simulations were conducted to provide the required input data for the failure hypothesis. Component samples were tested to verify the results of the QFH.

Findings - The load bearing capacity of journal bearings was analysed for different operating conditions by the use of the QFH. Results allow for the identification of critical and non-critical loading conditions and are in accordance with component test results.

Originality/value - Today's design guidelines for journal bearings do not consider a multi-axial stress state and actual stress distribution. The applied hypothesis enables consideration of multiaxiality inside the sliding surface layer, as well as determining the location of bearing fatigue due to material overload.
\end{abstract}

Keywords EHD, Multi-axial fatigue, Plain bearing, Quadratic failure hypothesis, TEHD, White metal

Paper type Research paper

\section{Introduction}

In mechanical engineering applications, plain bearings are subjected to increased thermal and dynamic loads. High dynamical loads often result in fatigue damage leading to shorter bearing life. Thus, there is a need for an improved methodology predicting bearing life and identifying critical operating conditions that lead to bearing failures. In today's bearing calculations, a specific pressure, the quotient of bearing load and projected surface, is taken into account as a design parameter for the determination of safe operating conditions (VDI 2204, 1992). However, multi-axial stress and non-proportional loading being present in plain bearings cannot simply be represented by a mere mean value. Hence, the present work aims to prove the applicability of the quadratic failure hypothesis $(\mathrm{QFH})$ in the design process of plain bearings considering the multi-axial stress state as design criteria.

The current issue and full text archive of this journal is available on Emerald Insight at: www.emeraldinsight.com/0036-8792.htm

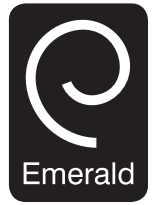

Industrial Lubrication and Tribology

$68 / 3$ (2016) 430-438

C Emerald Group Publishing Limited [ISSN 0036-8792]

[DOI 10.1108/ILT-08-2015-0119]
Predicting the fatigue strength of dynamically highly loaded, tin-based ( $\mathrm{Sn}$ ), white metal journal bearings is, at present, not possible. Several hypotheses have been suggested to predict the fatigue life of plain bearings, but their reliability has yet not been verified. The white metal sliding surface in high-revving hydrodynamic plain bearings is exposed to non-proportional multi-axial loading, with rotating principal axes in time (FVA 542-1, 2011). Classical failure criteria, such as the von Mises distortion energy criterion, cannot be applied to non-proportional loading. Shamsaei et al. (2010) among others have shown that these criteria often underestimate the typically observed shorter lives for non-proportional loading. Advanced failure criteria are capable to assess non-proportional load cases. In principle, the present multi-axial fatigue criteria can be sub-divided into three categories: hypotheses of the critical

The research for this paper was financially supported by Deutsche Forschungsgemeinschaft (DFG) and Forschungsvereinigung Verbrennungskraftmaschinen e.V. (FVV) in the research project JA 1940/ 4-1 / BR 1844/10-1 (FVV 1143). Sincere thanks to Gero Burghardt from the Institute for Machine Elements and Machine Design and Sascha Buthmann from the Institute of Material Applications in Mechanical Engineering, at RWTH Aachen University, Aachen, Germany for their help and inspiring discussions.

Received 18 August 2015

Revised 16 December 2015

Accepted 11 January 2016 
plane approach, integral approach and empirical criteria. In the integral approach, the equivalent stress is calculated as an integral of the stresses over all intersection planes of a volume element. The hypothesis of the effective shear stress (Simbürger, 1975) and the shear stress intensity hypothesis (SIH) (Zenner and Richter, 1977; Liu, 1991) are integral approaches, whereas in the critical plane approach, only the intersection plane with the most critical stress combination is considered. Critical plane approaches are regarded as reliable and robust in multi-axial fatigue life estimations. They are typically based on the maximum shear plane or the maximum principal plane failure mode. According to Fatemi and Shamsaei (2011), they can be classified in stress-, strain- and strain-stress- or energy-based models. The considered plain bearings are operated under high cycle fatigue (HCF) conditions; thus, plastic deformation can be regarded as located to the microscopic scale and might be seen as negligible and allow the use of stress-based yield criteria. Most stress-based criteria are derived from the studies of Gough and Pollard (1935), Sines (1959) and Findley (1959). Wang and Yao (2004) evaluated these criteria and found that they show decent correlation with multi-axial fatigue data under proportional loading. The correlation decreases as the degree of non-proportionality increases. Their applicability is often limited solely to ductile or respectively brittle deformation behaviour.

As a stress-based criterion, the QFH (El-Magd, 1974; Troost et al., 1987) combines the principal ideas of the aforementioned critical plane approach and the integral approach by calculating two failure values. These values can be distinguished as representing each one of these approaches. That makes it applicable to a wide range of materials from brittle to ductile deformation behaviour. For brittle materials, the normal stresses in the critical plane are decisive for failure, whereas the integration of the shear stresses in all intersection planes indicates the extent of plastic deformation which is known as failure critical for ductile materials. The failure values of both approaches are weighted by the ductility level $\tau_{\mathrm{W}} / \sigma_{\mathrm{W}}$, where $\tau_{\mathrm{W}}$ and $\sigma_{\mathrm{W}}$ are the fatigue endurance limits for torsional and axial loading, respectively. The QFH has shown good correlation between experimental and calculated results in the past for in-phase and out-of-phase multi-axial loading on a wide range of metals (Troost et al., 1988). In the recent past, the QFH was applied to plain bearing fatigue life estimations, for example, in the study by Beiss et al. (2011) and Nešić (2013). The here-presented revised calculation method makes QFH applicable to every integration point of the finite element (FE) calculation and considers the complete bearing loading over time.

To gain data on load capacity and material behaviour of the used white metal alloy, cyclic loading tests on bulk material samples were carried out. The multi-axial stress tensor in the bearing was computed by means of multi-body simulation and FE simulation considering elastohydrodynamic and thermal effects. Furthermore, journal bearings were subjected to fatigue tests to determine the service life and fatigue life under different operating conditions. Testing and simulation procedure is depicted in Figure 1. First, material data, describing the behaviour under dynamic compression and tensile loads, were determined. In addition to the material data, stress tenors in the
Figure 1 Evaluation procedure of QHF for fatigue limit prognosis of highly loaded white metal journal bearings

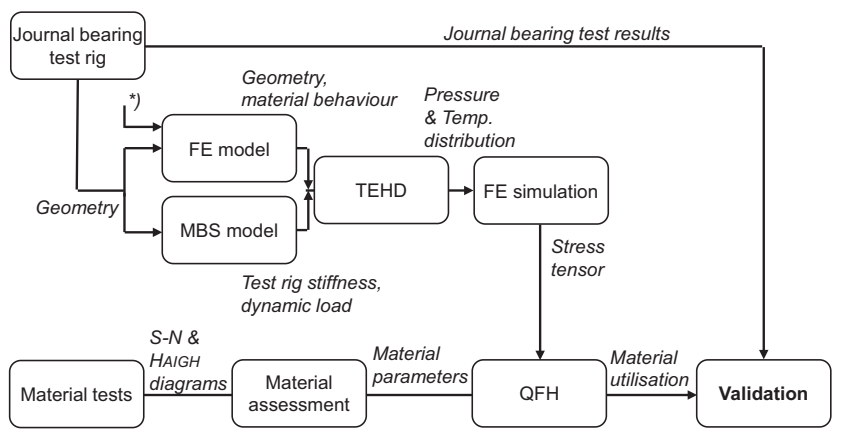

Notes: $\mathrm{MBS}=$ Multi-body simulation; TEHD $=$ Thermal elastohydrodynamic simulation; ${ }^{*}$ ) = Basic material properties e.g.: Modulus of elasticity, thermal conductivity, density, etc.

bearing material were computed. For verification, component tests with journal bearings were conducted.

To validate the $\mathrm{QFH}$ as a criterion, suitable to predict if operating conditions will lead to fatigue damage of white metal journal bearings, two different maximum dynamic load amplitudes were investigated.

\section{Theory}

Quadratic failure hypothesis

The idea behind the QFH was developed by Troost and El-Magd (1975) and El-Magd (1974) and extended by (Kaniut 1983) for three-dimensional applications. The key aspect is the formulation of a "quadratic potential" $F$ as a function of the position in space and time [equation (1)]:

$$
F(\vartheta, \theta, \rho, t)=\{\boldsymbol{\sigma}\}^{T}[\boldsymbol{P}]\{\boldsymbol{\sigma}\}
$$

In equation (1), $\sigma$ is the stress tensor, described as a $6 \times 1$ matrix in Voigt notation. $P$ describes the direction-dependent fatigue limit. The Euler angles $\vartheta, \theta$ and $\rho$ describe the orientation of the sectional plane and $t$ expresses the time dependence of the loading. Kaniut proposed a reformulation of the quadratic potential [equation (2)]. The first summand refers to the shear stress components of the tensor and the second summand to the normal stress components of the tensor:

$$
F(\vartheta, \theta, \rho, t)=\sum_{\substack{i, j=1 \\ i \leq j}}^{3} \frac{\left(\overline{\bar{\sigma}}_{\mathrm{a}}(\mathrm{t})\right)_{\mathrm{ij}}^{2}}{A_{\mathrm{ij}}^{2}}+(2-T) \sum_{\substack{i, j=1 \\ i \leq j}}^{3} \frac{\left(\overline{\bar{\sigma}}_{\mathrm{a}}(\mathrm{t})\right)_{\mathrm{ii}} \cdot\left(\overline{\bar{\sigma}}_{\mathrm{a}}(\mathrm{t})\right)_{\mathrm{ij}}}{A_{\mathrm{ii}} \cdot A_{\mathrm{ij}}}
$$

$\overline{\bar{\sigma}}_{\mathrm{a}}(\mathrm{t})$ is the respective stress amplitude of each component of the stress tensor. $A$ describes the direction-dependent fatigue behaviour for each stress component, as shown in equation (3) for normal stress components and in equation (4) for shear stress components. $T$ is a function of the ductility level [equation (5)]:

$$
i=j: A_{\mathrm{ij}}=\sigma_{\mathrm{W}}-c\left(\overline{\bar{\sigma}}_{\mathrm{m}}\right)_{\mathrm{ij}}-b\left(\overline{\bar{\sigma}}_{\mathrm{m}}\right)_{\mathrm{ij}}^{2}
$$




$$
i \neq j: A_{\mathrm{ij}}=\frac{\sigma_{\mathrm{W}}}{\sqrt{T}} \frac{\left(1-b \frac{\left(\overline{\bar{\sigma}}_{\mathrm{m}}\right)_{\mathrm{ij}}^{2}}{\sigma_{\mathrm{W}}}\right)^{2}-c^{2}\left(\frac{\left(\overline{\bar{\sigma}}_{\mathrm{m}}\right)_{\mathrm{ij}}}{\sigma_{\mathrm{W}}}\right)^{2}}{\sqrt{\left(1-b \frac{\left(\overline{\bar{\sigma}}_{\mathrm{m}}\right)_{\mathrm{ij}}^{2}}{\sigma_{\mathrm{W}}}\right)^{2}+\left(\frac{4}{T}-1\right) c^{2}\left(\frac{\left(\overline{\bar{\sigma}}_{\mathrm{m}}\right)_{\mathrm{ij}}}{\sigma_{\mathrm{W}}}\right)^{2}}}
$$

$\overline{\bar{\sigma}}_{\mathrm{m}}$ is the mean stress component. $\sigma_{\mathrm{W}}$ is the fatigue limit for axial loading without mean stress:

$$
T=\left(\frac{\sigma_{\mathrm{W}}}{\tau_{\mathrm{W}}}\right)^{2}
$$

The parameters $b$, equation (6), and $c$, equation (7), describe the mean stress effect. The parameter $p$ describes the bearable stress amplitude as a function of the mean stress and is empirically derived from the fatigue strength diagram (e.g. Haigh):

$$
\begin{gathered}
b=(1-p) \frac{\sigma_{\mathrm{W}}}{R_{\mathrm{m}}^{2}} \\
c=p \frac{\sigma_{\mathrm{W}}}{R_{\mathrm{m}}}
\end{gathered}
$$

The quadratic potential $F$ is calculated according to equation (2) for one load cycle (LC) of the bearing. The cycle is, therefore, divided in discrete time increments. For each time increment, the potential $F$ is calculated for each intersection plane, realized by axis rotation of the stress tensor around the Euler angles $\vartheta, \theta, \rho$. From this quadratic potential, a global maximum $\bar{F}_{\max }$ can be derived, representing the critical plane approach, and a maximal integral value $\widetilde{F}_{\max }$, representing the integral plane approach. Both maximum values are subsequently used to calculate the "Failure value" $F_{\mathrm{F}}$ in equation (8):

$$
F_{\mathrm{F}}=(1-a) \bar{F}_{\max }+2 a \widetilde{F}_{\max }
$$

In equation (8), the parameter $a$ is a function of the ductility level $T$ :

$$
a=\cos ^{2}\left(\frac{\pi}{2} \frac{\sqrt{3}-\sqrt{T}}{\sqrt{3}-1}\right)
$$

Depending on the ductility of the material, the critical plane approach proportion $\bar{F}_{\max }$ and the integral approach proportion $\widetilde{F}_{\max }$ are weighted, meaning that $F_{\mathrm{F}}$ for brittle material is dominated by $\bar{F}_{\max }$ and for ductile material dominated by $\widetilde{F}_{\max }$. The result is a scalar value. For $F_{\mathrm{F}} \epsilon$ $[0 ; 1]$, the continuum is deemed to be fatigue endurable. Values for $F_{\mathrm{F}}>1$ predict a failure within the finite life fatigue strength.

This procedure is coded as a post-processor for commercial FE tools and is applied to all Gauss integration points of the results of the later presented numerical FE solution. The output of the lifetime calculation is a two-dimensional contour plot, displaying the Failure value $F_{F}$ over the bearing circumference and width.

\section{Elastohydrodynamics}

In elastohydrodynamic lubrication (EHD), the hydrodynamic lubrication (HD), described by Reynolds (1886), as well as an elastic deformation of the contact surfaces as suggested by Ertel (Cameron, 1985) and Grubin (Grubin and Vinogradova, 1949), are considered.

The HD describes the behaviour of a lubricant in motion in multiple dimensions, taking into account the local change of parameters such as velocity or pressure. Thus, a change of density $\rho$ and, therefore, a change of dynamic viscosity $\eta$ influencing the local hydrodynamic pressure can be regarded. A simple approach to describe the dependence of dynamic viscosity on pressure has been published by Barus. In this approach, an exponential relationship between dynamic viscosity and pressure is postulated. In addition to the lubricant's behaviour, the EHD considers elastic deformations of the contact surfaces according to Hertz (1882), increasing the load bearing capacity.

\section{Thermal elastohydrodynamics}

In the thermal elastohydrodynamics (TEHD), the EHD contact is described with respect to the dependence of viscosity $\eta$ on temperature. The temperature is calculated locally and leads to a local change of pressure. A part of the TEHD is the calculation of temperature in the contact area considering the thermal properties of the surrounding bodies and fluid. The temperature is a result of friction power and shearing of the lubricant. Moreover, local temperatures are influenced by heat conduction and heat convection.

\section{Experimental testing}

The tests using bulk material samples were conducted to provide the required input data for the QFH, whereas the results of the component tests are compared to the $\mathrm{QFH}$ prognoses.

\section{Material and specimens}

The material under investigation is alloy SnSb12Cu6ZnAg, a bearing metal based on tin without lead, cadmium, nickel or arsenic, distributed by ECKA Granulate $\mathrm{GmbH} \&$ Co. KG (Ecka Granulate Essen $\mathrm{GmbH}, 2015)$. This alloy fulfils the current environmental requirements. Material and specimens were provided by Gleitlagertechnik Weißbacher $\mathrm{GmbH}$.

The used geometry of the specimens is shown in Figure 2. All bulk material samples have been machined out of a solid ring of bearing material which had been produced by centrifugal casting.

In Table I, the chemical composition of SnSb12Cu6ZnAg is given. A micrograph of etched SnSb12Cu6ZnAg is shown in Figures 2 and 3.

The intermetallic phases, $\mathrm{Cu}_{6} \mathrm{Sn}_{5}$ and $\mathrm{SnSb}$, lead to an increase in material strength because of precipitation hardening. Furthermore, antimony and bismuth lead to a solid solution hardening, which ensures a high fatigue strength (Hilgers, 1992). SnSb12Cu6ZnAg is rather brittle with an elongation at break of 1 per cent.

\section{Bulk material sample testing}

To determine the fatigue properties of the bearing alloy SnSb12Cu6ZnAg, cyclic stress controlled fatigue tests with a 
Figure 2 Geometry of specimens: Material tests

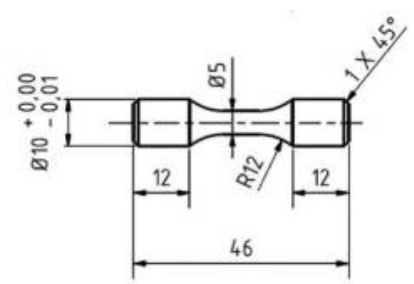

(a)

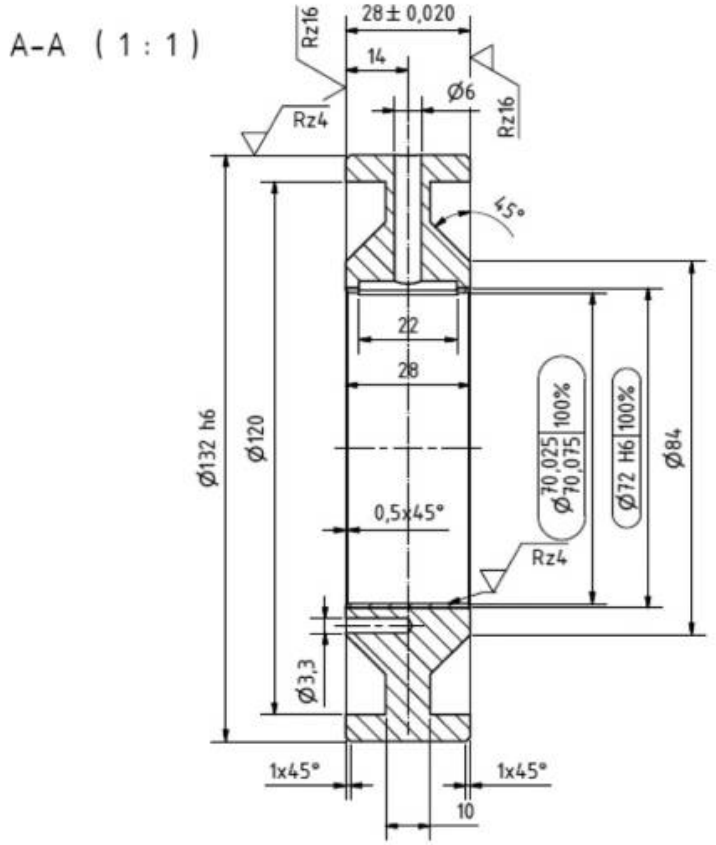

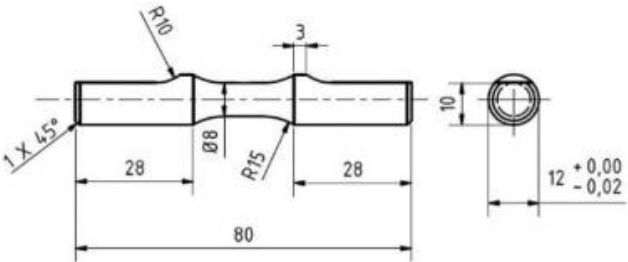

(b)

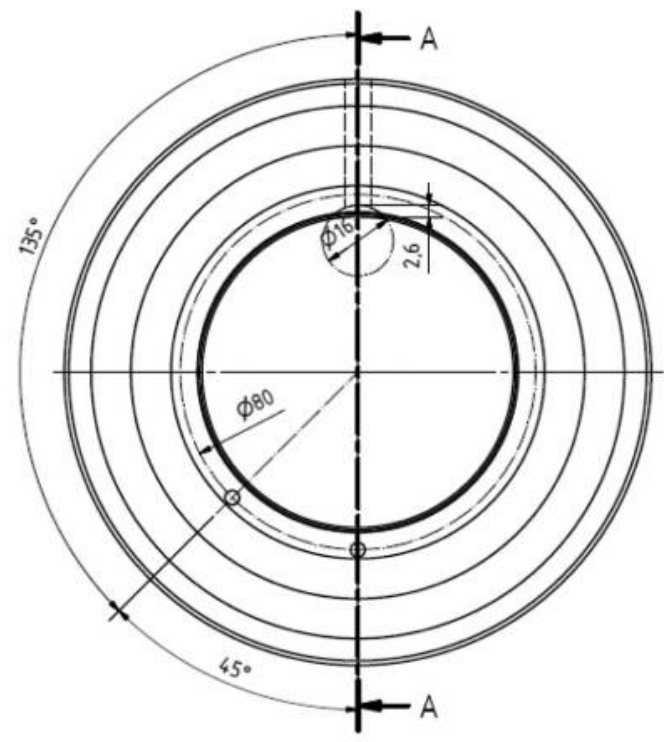

(c)

Notes: (a) Axial loading; (b) torsional loading; Component tests; (c) test bearing

Table I Chemical composition (wt. \%) of SnSb12Cu6ZnAg

\begin{tabular}{ccccc}
\hline $\mathrm{Sb}$ & $\mathrm{Cu}$ & $\mathrm{Zn}$ & $\mathrm{Ag}$ & $\mathrm{Sn}$ \\
\hline 12 & 6 & 0.6 & 0.1 & bal.
\end{tabular}

Figure 3 Light optical micrograph of etched SnSb12Cu6ZnAg

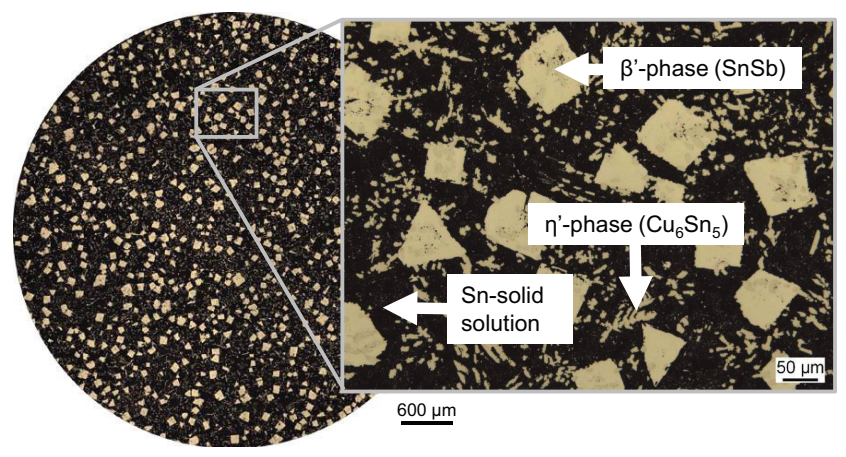

sinusoidal waveform were carried out. By varying the mean stress in discrete steps in the tension and pressure range, the influence of the mean stress of the bearable stress amplitude was investigated. These tests were performed for uniaxial loading at $R=-1$ and $R=0$ and for torsional loading at $R=-1$ for a sustainable number of cycles of $N_{\mathrm{f}}=10^{7}$. The fatigue limit was analysed statistically and depicted in an S-N curve, each populated with 20 specimens.

\section{Component testing}

Component tests were carried out on a journal bearing test rig (Figure 4).

The test bearing is located between two support bearings. The tested bearings had a ( $W / D$ ) ratio of 0.4 and an inner diameter of $70 \mathrm{~mm}$. The sliding layer of $1 \mathrm{~mm}$ thickness was produced by centrifugal casting. The bearings were subjected to a high sinusoidal load $F_{R}$ (Figure 5), resulting in a pulsating pure compressive stress. The load was applied by two hydraulic cylinders. Each cylinder is tilted $45^{\circ}$ from the vertical axis. Thus, a higher resulting force can be applied unlike by the use of a single hydraulic cylinder and allows for the reduction of the necessary installation space. The load frequency in the component tests was $49 \mathrm{~Hz}$, both cylinders 
Figure 4 Journal bearing test rig

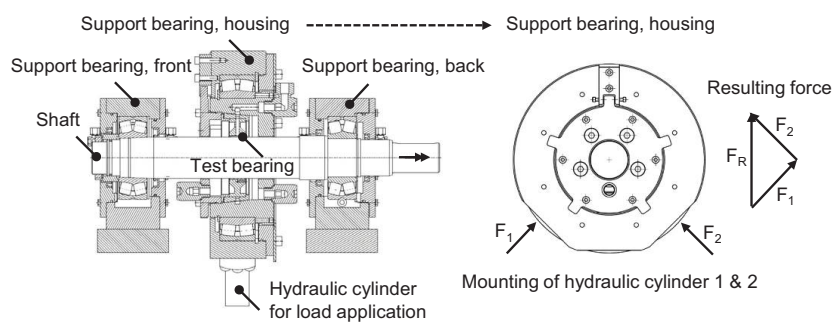

Figure 5 Dynamic load applied on journal bearing in component tests

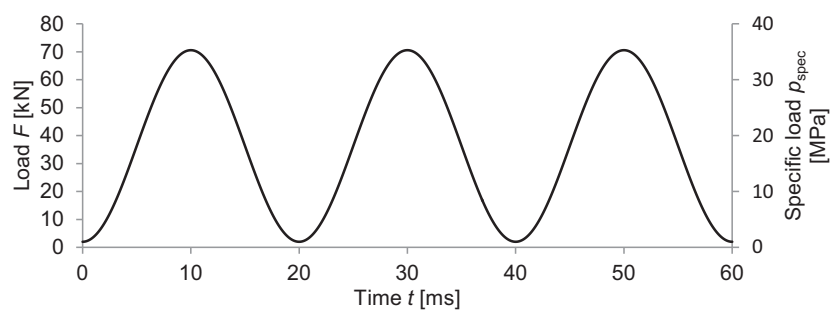

operated without phase shift. The test rig operated at 3,000 $\mathrm{rpm}$, which is equivalent to a sliding velocity of $11 \mathrm{~m} / \mathrm{s}$. The test oil is customary turbine oil with a kinematic viscosity $\nu$ of $100 \mathrm{~mm}^{2} / \mathrm{s}$ at $40^{\circ} \mathrm{C}$ and $10.6 \mathrm{~mm}^{2} / \mathrm{s}$ at $100^{\circ} \mathrm{C}$.

The component tests were carried out with a preconditioning phase and subsequent test phase (Figure 6). The preconditioning took place in three steps in the first $12 \times$ $10^{6}$ LCs. Each step lasted for $4 \times 10^{6} \mathrm{LC}$ and the applied dynamic load amplitude was increased successively. The maximum dynamic load amplitude was increased gradually, beginning with $\bar{p}_{\text {dyn }}=F_{\mathrm{p}, \max } /(\mathrm{W} \times \mathrm{D})=5 \mathrm{MPa}$ followed by 10 and $20 \mathrm{MPa}$. During the preconditioning phase, the surface roughness of all bearings is smoothed under a moderate load, and the bearing temperature due to shear and friction in the sliding contact is increased step-wise with increasing load amplitude. Thus, a bearing damage due to thermo-shock has been prevented. After the preconditioning phase, the testing phase started.

The journal bearings were provided with bore holes to measure the bearing temperature $4 \mathrm{~mm}$ beneath the sliding layer material. As a criterion to detect fatigue damage, a sudden increase in bearing temperature was chosen.

Figure 6 Test procedure of component tests

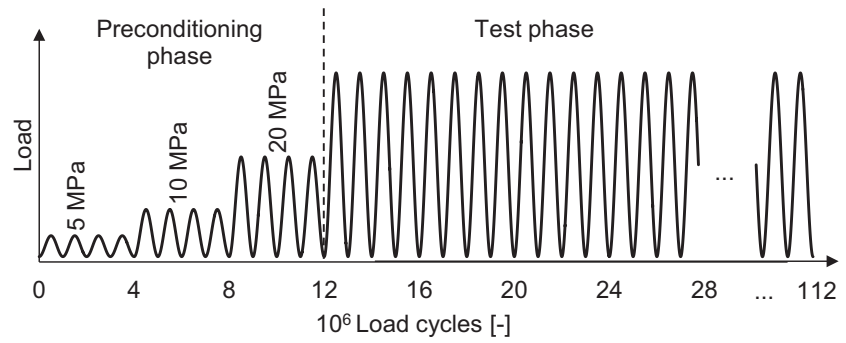

\section{Results}

\section{Bulk material test results}

The material fatigue strengths used for this study are shown in Figure 7, where the description of the bearable load amplitudes as a function of the mean stress is depicted in a fatigue strength diagram according to Haigh. The diagram shows the bearable stress amplitude $\sigma_{A}$ normalised on the fatigue limit $\sigma_{W}$ plotted against the corresponding mean stress $\sigma_{m}$ normalised to the ultimate tensile strength $R_{m}$. The considered temperatures reflect the operating temperature of the bearing between $90^{\circ} \mathrm{C}$ and $100^{\circ} \mathrm{C}$. Further, the approaches to describe the mean stress effect proposed by Goodman $(p=1)$ and Gerber $(p=0)$ are shown in the diagram. The parameter $P$ relates to equations (6) and (7). It is noticeable that the fatigue behaviour of the material can be described accurately by the Goodman line. Therefore, the parameter $p$ was set to $p=1$.

\section{Component test results}

Results of the component tests are presented as S-N diagram in Figure 8. The $12 \times 10^{6} \mathrm{LC}$ of the preconditioning phase are not counted in the displayed results.

The tests were performed as summarised in Table II.

The tests were conducted according to the aforedescribed procedure until the defined fatigue strength limit was reached or the temperature signal detected a fatigue damage. In the tests, the oil volume flow into the plain bearing was adopted to adjust the measured bearing temperature to $90^{\circ} \mathrm{C}$.

Figure 7 Fatigue strength diagram for SnSb12Cu6ZnAg at $T=$ $90^{\circ} \mathrm{C}$ and $T=100^{\circ} \mathrm{C}$

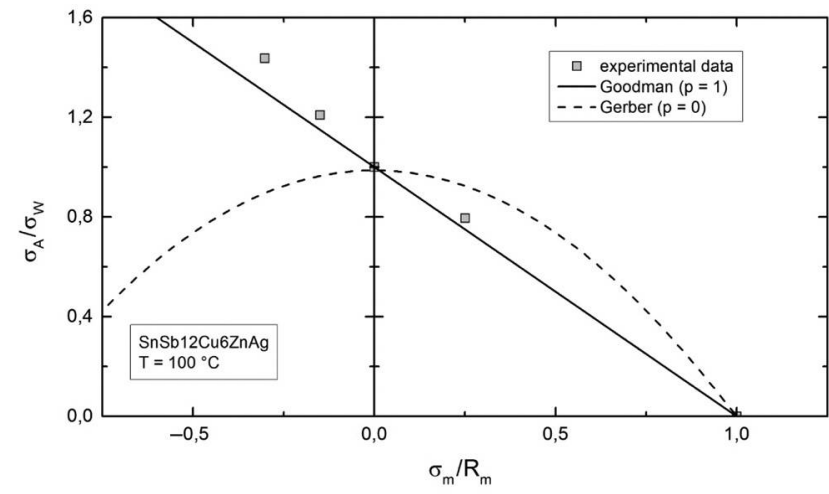

Source: Nešić (2013)

Figure 8 Results from component tests

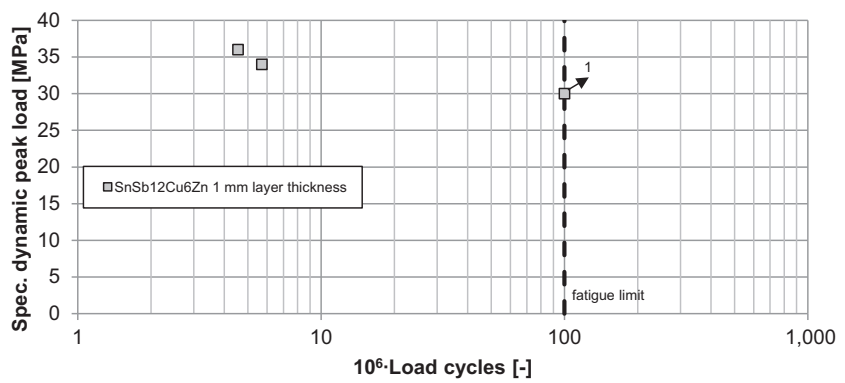


Prediction of fatigue limit of journal bearings

Christopher Sous, Henrik Wünsch, Georg Facobs and Christoph Broeckmann

Table II Performed component tests; endured load cycles without preconditioning phase

\begin{tabular}{lccc}
\hline Test ID & $\begin{array}{c}\text { Specific dynamic } \\
\text { peak load (MPa) }\end{array}$ & $\begin{array}{c}\text { Endured load } \\
\text { cycles (-) }\end{array}$ & Damage \\
\hline Test 01 & 36 & $4.55 \times 10^{6}$ & Yes \\
Test 02 & 34 & $5.71 \times 10^{6}$ & Yes \\
Test 03 & 30 & $100 \times 10^{6}$ & No \\
\hline
\end{tabular}

The presented results from the component tests in Figure 8 indicate that for SnSb $12 \mathrm{Cu} 6 \mathrm{ZnAg}$ with a $1 \mathrm{~mm}$ layer thickness, there is a distinct change in the endured LCs between $30 \mathrm{MPa}$ and $36 \mathrm{MPa}$ specific dynamic peak load. This change has been confirmed by tests on the same test rig in other research projects (Jacobs et al., 2009) for SnSb12Cu6ZnAg with $2 \mathrm{~mm}$ layer thickness.

\section{Simulation results}

Modern simulation tools enable the user to calculate the hydrodynamic pressure regarding the influence of elastic deformation of and temperature distribution on the contact surfaces. The simulation tool used by the authors is Excite Power Unit Version 2014.1 (AVL Excite Power Unit, AVL List $\mathrm{GmbH}$, Graz, Austria, 2015). This software combines multi-body simulation (MBS), for example, of the test rig, with TEHD simulation, for example, of the sliding contact.

In the simulations, the journal bearing test rig has been depicted as MBS with condensed FE bodies of shaft, bearing and bearing housing. Thus, it is possible to take influences like the test rig stiffness into consideration while computing the pressure and temperature distribution. The simulation runs until a steady state condition is reached. In Figure 9, the curve for the calculated maximum oil film temperature in the TEHD contact is presented, and the steady state condition is highlighted. The temperature calculation takes into account the heat conduction in radial direction into the bearing adjacent structure and the heat convection in all three directions, as well as the heat conduction into the lubricant (AVL List GmbH, 2013).

The calculated pressure and temperature distributions were extracted from the MBS/TEHD for discrete sample points. The pressure distribution regards oil film pressure, as well as asperity contact pressure. These results are imprinted onto the FE body in multiple successive steps to calculate the stress tensors for all elements over one LC. The software used is Abaqus Version 2013 (Dassault Systèmes, 2015).

The calculated stress tensor changes for different applied loads. To emphasise the influence of an increase in load, the

Figure 9 Curve for maximal oil film temperature in journal bearing under dynamic load

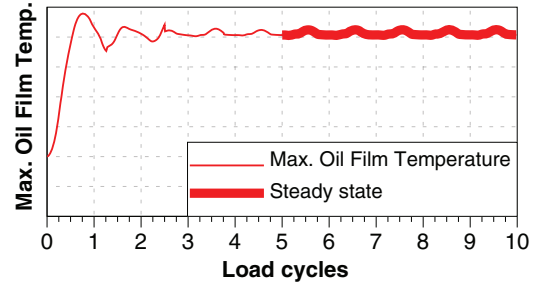

calculated stresses, as well as temperature of one element over one LC, are shown in Figures 9 and 10.

The magnitudes of the displayed stresses changed significantly during one full LC. The calculated stresses of the evaluated element were 10 per cent $\left(\sigma_{\mathrm{y}}\right)$ up to 13 per cent $\left(\sigma_{\mathrm{x}}\right)$ higher at $36 \mathrm{MPa}$ in comparison to $30 \mathrm{MPa}$. The temperature has only little influence on the calculated stresses, which can be seen at the start and end of the depicted LC. The temperature of both LCs varies up to 6 per cent, but the ensued stresses do not differ from one another at the start and end of the simulated LC.

\section{Discussion}

Simulations were performed for $30 \mathrm{MPa}$ and $36 \mathrm{MPa}$ specific dynamic peak load. Referring to the results of component tests shown in Figure 8, these simulations correspond to the component tests. Between these load cases, a significant change in endured number of LCs occurred. The cause is either to be found in the ensued absolute pressures or the thermal loads. On the one hand, the absolute pressures may lead to an overload of material load capacity, exceeding the material strength. Thermal loads, on the other hand, can also induce stresses inside the sliding layer due to varying expansion coefficients of the sliding layer and the steel back. As the thermal coefficients of steel and white metal differ only slightly from one another, the change in temperature does not lead to a significant change in stresses. Hence, thermal load as failure cause was excluded.

According to the Reynolds equation, the oil film thickness depends on the ensued pressure or respective load. An increase in load results in a decrease of oil film thickness, which may lead to asperity contact. The peak oil film pressure increased up to approximately 10 per cent by a change from 30 to $36 \mathrm{MPa}$ (Figure 11). The maximum oil film temperature increased by 6 per cent, resulting in lower viscosity and, therefore, even lower film thickness in the sliding contact.

The bearing loaded with $36 \mathrm{MPa}$ showed a fatigue crack in the bearing middle (Figure 12). The orientation of the crack in a near $45^{\circ}$ angle is typical for fatigue damage. Asperity contact arose as soon as the crack in the bearing surface opened. The asperity contact area is characterised by the brighter colour of the surface. This is caused by further smoothing of the bearing surface to a mirror-like appearance. Asperity contact is restricted to a small portion of the surface and only to an area behind the crack relative to the direction of rotation. Thus, a material overload and not asperity contact seems to be the cause for bearing damage at $36 \mathrm{MPa}$.

Figure 10 Change of stress tensor components due to dynamical loading as well as change in applied load
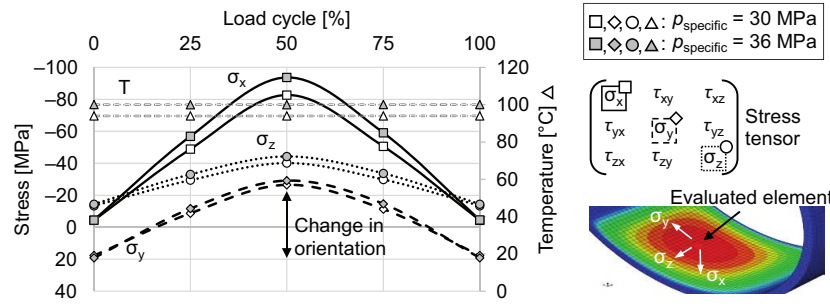
Figure 11 Peak oil film pressure and temperature for 30-MPa- and 36-MPa-specific dynamic peak load for one load cycle

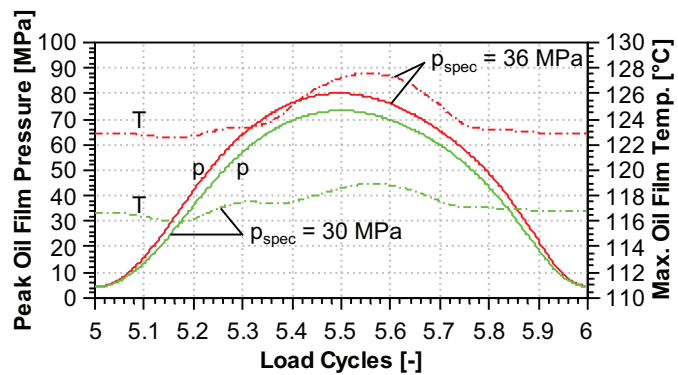

Figure 12 Journal bearing with fatigue damage, material: SnSb12Cu6ZnAg, specific dynamic peak load: $36 \mathrm{MPa}$
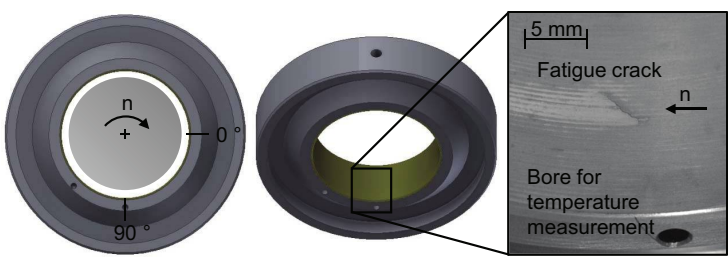

The QFH approach enables an evaluation of the loading while considering the orientation-dependent fatigue parameters of the material. According to equation (8), the distribution of the failure value $F_{F}$ on the developed sliding surface of the lower half of the bearing is shown in Figures 13 and 14.

For $30 \mathrm{MPa}$, the maximum failure value $F_{F}$ of 0.97 is reached at a circumferential angle of $107^{\circ}$ and in the axial middle of the sliding surface. For $36 \mathrm{MPa}$, the maximum failure value $F_{F}$ of 1.19 is reached at a circumferential angle of $103.5^{\circ}$ and (also) in the axial middle of the sliding surface.

Figure 13 Results of QFH calculation for dynamic peak load of 30 $\mathrm{MPa}$

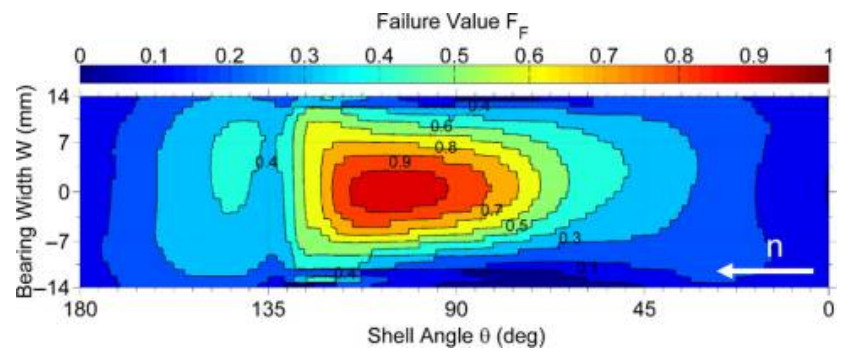

Figure 14 Results of QFH calculation for dynamic peak load of 36 $\mathrm{MPa}$

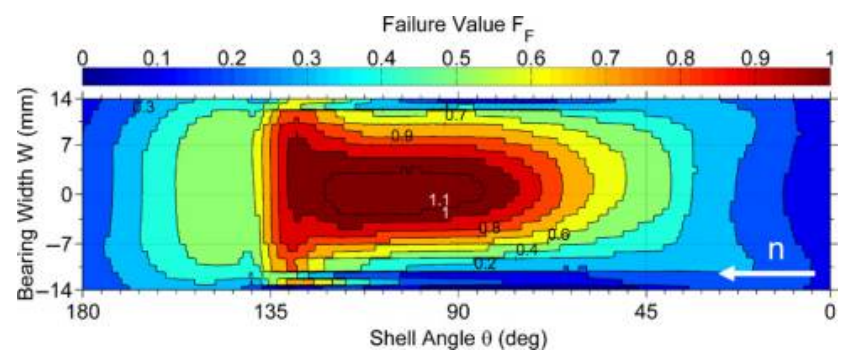

As it is assumed that a value $F_{F} \geq 1$ leads to damage in the continuum, it can be shown that for $30 \mathrm{MPa}$, no bearing failure is expected, as $F_{F}$ does not exceed a value of 1 . In accordance to the experiment, no failure appears. According to VDI 2204 (VDI 2204, 1992), a guideline for bearing design calculation, this load case should be most unsafe. It says that for the given temperature - material combination only a specific load of $8.3 \mathrm{MPa}$ should be applied.

For $36 \mathrm{MPa}, F_{F}$ does exceed a value of 1 in a wide area of the sliding surface, represented by the dark red area in Figure 14. As expected, crack formation was observed in the experiment (Figure 12). The location of crack initiation in the experiment matches the location of the calculated maximum value of $F_{F}$ at $\theta=101^{\circ}$.

For both load cases, the failure value shows an asymmetric distribution in the width direction. The reason for that is the consideration of the stiffness of the casing including the interference fit of the journal bearing in the FE calculation. The asymmetric loading is expressed in an asymmetric failure value.

Two material parameters were used which have a major influence on the calculation of $F_{F}$. The ductility influence of brittle and ductile material behaviour on the failure value $F_{F}$ is in accordance with equation (5) represented by the parameter $T$. For the presented calculation, $T$ was set to 3.2, which stands for a rather ductile material behaviour (Kaniut, 1983). In Figure 15, a scanning electron microscope (SEM) picture is shown. This SEM picture is a detail of the fracture surface of the fatigue damage shown in Figure 12. A major area of that surface shows typical signs of a microscopic ductile fracture. Typical for a ductile fracture mechanism are dimple like structures. The large areas of ductile fracture appearance make it reasonable to expect that the failure mechanism is dominated by microscopic plastic deformations.

The mean stress sensitivity of the material is described by the parameter $p$. The parameter $p$ was set to 1 in accordance to Figure 7.

\section{Conclusions and outlook}

FE simulations using results of multi-body and thermal elastohydrodynamic simulation were performed to describe

Figure 15 SEM picture of the fracture surface of a journal bearing with fatigue damage, material: SnSb12Cu6ZnAg, specific dynamic peak load: $36 \mathrm{MPa}$

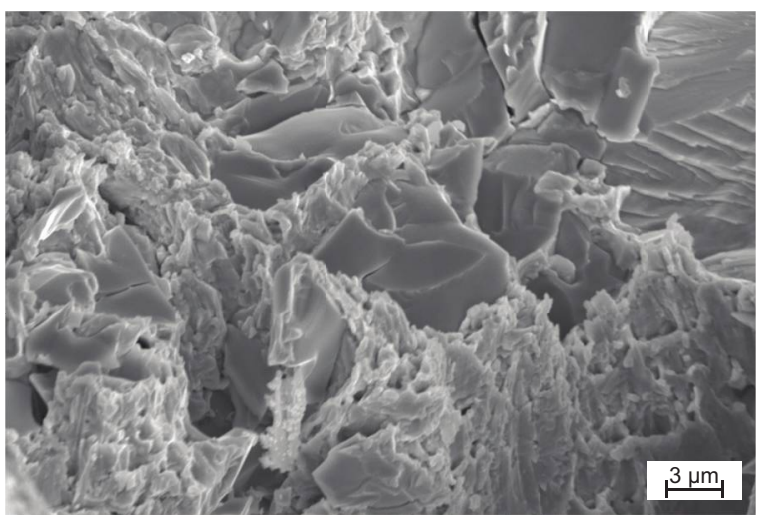


the stress state in the sliding surface of a journal bearing. In these simulations, the pressure and bearing temperature distribution have been considered. For discrete times, the stress tensor in the sliding surface was extracted from the FE simulations at every integration point of each element. The extracted multi-axial stress tensor was input to the QFH. Two load cases were regarded in this study. In the simulations of both load levels, an increase in stresses of up to 13 per cent was calculated. These calculated stresses were input parameters to the $\mathrm{QFH}$ to predict safe or unsafe operating conditions. To compare the simulation results with experimental data, bearing tests were conducted on a test rig with the same geometry and boundary conditions as in the simulations. The bearing tests have shown that one load level leads to a fatigue crack in the sliding surface before reaching the fatigue limit of $100 \times 10^{6}$ LCs. Results from simulations and experimental tests are consistent. The QFH could be applied to predict safe as well as unsafe operating conditions as observed in the bearing tests. Furthermore, safe operating conditions have been predicted for a load case that should be most unsafe, according to the bearing design guideline VDI 2204.

Bearing design guidelines differentiate between constant and dynamic loads by increasing a safety parameter in case of dynamic loads. Thus, a possible increased load bearing capacity due to, for example, no creep deformation as a result of dynamic loading is neglected. The bearings discussed in this paper were provided with a layer thickness of $1 \mathrm{~mm}$. Contour measurements did not show any plastic deformation for these bearings. It is presumed that the steel backing ensures a certain stiffness of the composite of white metal and steel backing. Contour measurements of thicker layers up to $5 \mathrm{~mm}$, which are not discussed in this paper, did show a significant plastic deformation. The consideration of plasticity in the fatigue life assessment of bearings with thick sliding layers makes further studies necessary. In particular, the study of microplasticity within the layer would make significant contribution to understand the damage mechanisms. Moreover, a view on the microplasticity could clarify the influence of the microstructure on the fatigue behaviour of bearing metal.

\section{References}

AVL List GmbH (2013), Excite Power Unit Theory, AVL List GmbH, Graz, Austria, p. 37.

Beiss, P., Gold, P.W., Nešić, D. and Limmer, M. (2011), Abschlussbericht BE 1728/16-1 / GO 684/12-1, RWTH Aachen University, Institute for Machine Elements and Machine Design \& Institute for Material Applications in Mechanical Engineering, Aachen, Germany, Ermüdungsmechanismen und Lebensdauer Dynamisch Hoch Belasteter Gleitlager.

Cameron, A. (1985), "Righting a 40-year-old wrong: a. M. Ertel - the true author of 'Grubin ehl' solution", Tribology International, Vol. 18 No. 2, p. 92.

Dassault Systèmes, (2015), Abaqus, Vélizy-Villacoublay, Cedex.

Ecka Granulate Essen GmbH (2015), Gleitlagerlegierung ECKA TEGOSTAR, Essen.
El-Magd, E. (1974), Versagensbedingung bei Mehrachsiger Schwingender Beanspruchung Metallischer Werkstoffe, AachenHabilitation, RWTH, Aachen.

Fatemi, A. and Shamsaei, N. (2011), "Multiaxial fatigue an overview and some approximation models for life estimation", International fournal of Fatigue, Vol. 33 No. 8, pp. 948-958.

Findley, W.N. (1959), "A theory for the effect of mean stress on fatigue of metals under combined torsion and axial load or bending", Fournal of Engineering for Industry, Vol. 81 No. 4, pp. 301-306.

FVA 542-1 (2011), Final Report FVA-Project: Lebensdauerkriterien Innovativer Werkstoffe für hochtourige und hochbelastete Gleitlager, FVA 542-1, Frankfurt a.M.

Gough, H.J. and Pollard, H.V. (1935), "The strength of metals under combined alternating stresses", Proceedings of the Institution of Mechanical Engineers, Vol. 131 No. 1, pp. 3-103.

Grubin, A.N. and Vinogradova, I.E. (1949), Fundamentals of the Hydrodynamic Theory of Lubrication of Heavily Loaded Cylindrical Surfaces, Translation No. 337 into English by the Department of Science and Industrial Research, Vol. 30, Central Scientific Research Institute for Technology and Mechanical Engineering.

Hertz, H. (1882), "Über die Berührung fester elastischer Körper”, fournal für die reine und angewandte Mathematik, Vol. 92, pp. 156-171.

Hilgers, W. (1992), Gleitlagertechnik: Gleitlagerwerkstoffe, Th. Goldschmidt AG, Essen.

Jacobs, G., Limmer, M., Gold, P.W. and Rombach, V. (Eds) (2009), Versuche zur Ermüdungs-Lebensdauer Dynamischer Hoch Beanspruchter Radialgleitlager, Reibung, Schmierung und Verschleiß Forschung und Praktische Anwendungen, Vol. 62, Ges. für Tribologie, Aachen.

Kaniut, C. (1983), "Zur Betriebsfestigkeit metallischer Werkstoffe bei mehrachsiger Beanspruchung”, Dissertation, RWTH, Aachen.

Liu, J. (1991), "Beitrag zur Verbesserung der Dauerfestigkeitsberechnung bei mehrachsiger Beanspruchung”, Dissertation, Fakultät für Bergbau, Hüttenwesen und Maschinenwesen, Technischen Universität Clausthal.

Nešić, D. (2013), "Entwicklung und Charakterisierung hochfester umweltfreundlcher Gleitlagerlegierungen auf Sn-Basis", Dissertation, RWTH Aachen, Aachen.

Reynolds, O. (1886), "On the theory of lubrication and its application to $\mathrm{Mr}$ Beauchamp Tower's experiments, including an experimental determination of the viscosity of olive oil", Philosophical Transactions of the Roval Societv of London, Vol. 177, pp. 157-234.

Shamsaei, N., Gladskyi, M., Panasovskyi, K., Shukaev, S. and Fatemi, A. (2010), "Multiaxial fatigue of titanium including step loading and load path alteration and sequence effects", International fournal of Fatigue, Vol. 32 No. 11, pp. 1862-1874.

Simbürger, A. (1975), "Festigkeitsverhalten zäher Werkstoffe bei einer mehrachsigen, phasenverschobenen Schwingbeanspruchung mit körperfesten und veränderlichen Hauptspannungseinrichtungen", LBFReport No. FB-121, Fraunhofer-Gesellschaft. 
Sines, G. (1959), Behavior of Metals Under Complex Static and Alternating Stresses, Metal Fatigue, McGraw-Hill, New York, NY.

Troost, A., Akin, O. and Klubberg, F. (1987), "Dauerfestigkeitsverhalten metallischer Werkstoffe bei zweiachsiger Beanspruchung durch drei phasenverschoben schwingende Lastspannungen", Konstruktion, Vol. 39 No. 12 , pp. 479-488.

Troost, A., Akin, O. and Klubberg, F. (1988), "Zur Dauerfestigkeit metallischer Werkstoffe bei zweiachsig synchron und phasenverschoben schwingender Beanspruchung", Materialwissenschaft und Werkstofftechnik, Vol. 19 No. 12, pp. 406-407.

Troost, A. and El-Magd, E. (1975), "Allgemeine Formulierung der Schwingfestigkeitsamplitude in Haighscher Darstellung", Materialprüfung/Materials Testing, Carl Hanser, München, Munich, Germany, pp. 759-764.

VDI 2204 (1992), Auslegung von Gleitlagerungen, Verein Deutscher Ingenieure, Düsseldorf.

Wang, Y.-Y. and Yao, W.-X. (2004), "Evaluation and comparison of several multiaxial fatigue criteria", International Fournal of Fatigue, Vol. 26 No. 1, pp. 17-25.

Zenner, H. and Richter, I. (1977), "Eine Festigkeitshypothese für die Dauerfestigkeit bei beliebigen Beanspruchungskombinationen", Konstruktion, Vol. 29 No. 1, pp. 11-18.

\section{About the authors}

Christopher Sous studied at RWTH Aachen University, Aachen, Germany and received the MSc degree in 2012 in mechanical engineering. Ever since then, he has been working in the Tribology department at the Institute for Machine Elements and Machine Design, at RWTH Aachen University, Aachen. In 2014, he was appointed as a Group Leader of the Plain Bearing Group. In his studies, he investigates the influence of material and operating conditions on fatigue limit of plain bearings. Christopher Sous is the corresponding author and can be contacted at: sous@ime.rwth-aachen.de

Henrik Wünsch studied at RWTH Aachen University, Aachen, Germany and received his diploma in 2013 in mechanical engineering. Since then, he has been working in the group of Fatigue and Fracture Mechanics at the Institute for Material Applications in Mechanical Engineering, at RWTH Aachen University, Aachen. In his studies, he investigates the fatigue behaviour of metals and develops a method for the lifetime prediction of plain bearings.

Georg Jacobs received the Diplom-Ingenieur degree in 1989 at RWTH Aachen University, Aachen, Germany. From 1989 until 1996, he was employed at today's Institute for Fluid Power Drives and Controls (then: Institute for Hydraulic and Pneumatic Drives and Controls, IHP), at RWTH Aachen University. In 1993, he received his PhD degree on a thesis with the topic "Wear Behavior of Hydraulic Pumps and Valves During Operation in Particle-Contaminated Oil" and was appointed as a Senior Engineer. In the years 1996 to 2008, he taught Construction of Fluid Power Machinery and Components at RWTH Aachen University. From 1996 until 1997, Professor Jacobs worked as the Product Business Unit Manager "Großpressen" for Müller Weingarten AG in Weingarten. In 1997, he joined the Mannesmann Rexroth AG and was the Head of the Application Centre Industrial Hydraulics until 2001. Subsequent to this, he took over the Head of Development in the product field of axial piston machines at the newly formed Bosch Rexroth AG. Simultaneously, he took over the technical management of Brueninghaus Hydomatik GmbH. He was the Spokesman for the product field "Drives" with the special responsibility for the coordination of development of gears, hydraulic pumps and motors from 2005 to 2008 . He was also a Member of the division management "Hydraulic" since 2006. In October 2008, Professor Jacobs was appointed as the Head of the Chair and Institute for Machine Elements and Machine Design.

Christoph Broeckmann, after receiving his diploma in Mechanical Engineering at the Ruhr-University Bochum, Germany in 1990, worked with the Institute of Materials Science at Bochum until 2000, since 1996 as a Senior Scientist. He got his $\mathrm{PhD}$ in 1994 on a thesis on the fracture of carbide-rich steels. In 2000, Broeckmann got his lecture qualification (habilitation) based on a work on creep of particle reinforced materials. In 2000, he moved to the machine factory Köppern $\mathrm{GmbH} \&$ Co. KG in Hattingen where he first was responsible for material- and design-related research and development. Since 2003, he became the Managing Director of "Köppern Entwicklungs GmbH", a subsidiary dedicated to the development, production and delivery of large, powder metallurgically produced wear parts. Broeckmann joined RWTH Aachen University as a Professor in 2008. Since 2009, he is the Head of the Institute for Materials Applications in Mechanical Engineering.

For instructions on how to order reprints of this article, please visit our website: www.emeraldgrouppublishing.com/licensing/reprints.htm Or contact us for further details: permissions@emeraldinsight.com 